\title{
MARI, Tommaso. Pauca de barbarismo collecta de multis: studio ed edizione critica. Pisa: Edizioni ETS, 2017. 146 p.
}

\author{
Everton Grein \\ Universidade Estadual do Paraná, União da Vitória, Paraná / Brasil \\ evgrein@gmail.com
}

Nos últimos anos, o crescente interesse de linguistas e historiadores pelos grammatici latini tem evidenciado ao menos três fatores cruciais a serem considerados em seu conjunto e importância: a) a relevância histórica de seus autores e obras; b) a perspectiva linguística da moderna filologia acerca destas obras clássicas; c) o contributo literário destas produções.

De fato, desde a monumental edição de Heinrich Keil (18551880, reimp. Hildesheim, 1961, 8 v.), o corpus de textos atribuídos aos grammatici latini, constituído por um conjunto de manuais e tratados de gramática, escritos fundamentalmente entre os séculos III-VIII d.C., apresenta um amplo leque de interesses. Notadamente, deve-se pontuar aqui que seus autores e obras permitem um mapeamento da história das ideias linguísticas do Ocidente, cuja tradição posterior foi cara aos autores da Idade Média, especialmente àqueles centrados nas obras de Donato e Prisciano. Por outro lado, merece destaque que os preciosos fragmentos preservados e recolhidos por Keil oferecem interesses não somente filológicos, mas também literários, filosóficos e técnicos, podendo ser comparados com a tradição direta de textos conservados.

A obra dos gramáticos latinos evidencia igualmente - desde o século III - uma forte tendência ao chamado latim tardio, verificado a partir dos estrangeirismos, dos usos do latim familiar, ou mesmo através das gírias e expressões hodiernas das camadas menos letradas do mundo latinófono. Ao mesmo tempo, registre-se que este latim, em seus usos e 
formas, evoca igualmente discussões filosóficas acerca da natureza e do funcionamento da língua, denotando, ao fim e ao cabo, sua aplicabilidade no sentido prático do ensino durante a Antiguidade Tardia e Idade Média.

Notadamente, do ponto de vista histórico, a leitura e análise dos textos e contextos de suas respectivas produções permitem-nos complementar o conhecimento em torno da realidade histórica, social e cultural da época em que foram produzidos, bem como nos autorizam a ampliar nosso horizonte acerca de como seus autores concebiam e integravam o saber em sua época. Deve-se observar que os gramáticos latinos não foram simplesmente transmissores de regras ou normas linguísticas, pois eles também falavam a língua de seu tempo, atestando variações sociais dos usos e elementos característicos de seu dia a dia, refletindo ou criticando a formação de padrões linguísticos e sociais de sua época.

As características fundamentais de nossa concepção moderna de linguagem por vezes incidem sobre o processo evolutivo da língua, suas relações, dinâmica e historicidade, processos estes concernentes à diacronia da língua. A recuperação das obras dos gramáticos latinos traz à baila a perspectiva linguística da moderna filologia acerca dos problemas suscitados por estes autores. O valor filológico destas obras não está somente avalizado por razões intrinsecamente linguísticas.

Todavia, também se deve considerar o valor literário destas obras, muito embora o próprio conceito de literatura seja amplamente discutível para a época. A reflexão sobre a palavra escrita não deve ser entendida somente como um apanágio da gramática. Existem, pois, inúmeros meandros num texto escrito que traduzem as atitudes, formas e elementos das sociedades que o forjaram. O processo da escrita não pode ser dissociado de seu tempo, pelo contrário. Escrever um texto é imergir num conjunto de procedimentos que obedecem não somente aos padrões ou normas internas, mas, sobretudo, externas, em suas elaborações. Um texto é, antes de qualquer coisa, uma manifestação tácita do conjunto de elementos (culturais, políticos, sociais, religiosos, etc.) que o possibilitam enquanto tal, portanto, um processo de longa duração. A ausência do texto é também a ausência de quaisquer possibilidades de projetarmos uma 
visão mais acurada sobre os indivíduos ou grupos que os produziram. Um texto é uma manifestação simbólica de uma sociedade.

A delicada operação de devolver voz aos textos antigos apresenta, por certo, diversas imbricações. As dificuldades que se colocam nesse processo traduzem, de fato, a multiplicidade de elementos com os quais muitas vezes o estudioso se depara: erros, imperfeições, correções, alterações, enfim, um infinito de possibilidades que a própria língua pode apresentar. Foi nesse sentido que veio a lume, recentemente, uma das obras mais importantes do período medieval, conhecida sob o título de Pauca de barbarismo.

Trata-se de uma compilação gramatical da época carolíngia (séculos VII-IX) e refere-se aos escritos de numerosos gramáticos da Antiguidade tardia, basicamente comentando seus "uitia et uirtutes orationis". Estudada e editada por Tommaso Mari com o título Pauca de barbarismo collecta de multis, o volume em questão é a editio princeps da obra e está estruturado em duas partes: "introdução" e "texto". A primeira parte compreende nove capítulos: i. A obra; ii O manuscrito; iii. O estema; iv. As fontes gramaticais; v. As fontes literárias; vi. Texto afim e coetâneo; vii. A língua; viii. Contextualização da obra; ix. Critério editorial.

Tommaso Mari, após a apresentação inicial da obra, retoma pontualmente as características do manuscrito pela unidade codicológica de Leiden, Bibliothek Der Rijksuniversiteit, Voss. Lat. Q33, f. 160 r (mss. V), datada do século IX, destacando sua limitada tradição manuscrita, confrontando-o com outros quatro manuscritos: Bamberg, Staatliche Bibliothek, Class. 30 (M.V.18), ff. 56v.-70v. (século IX, mss. B); Leiden, Bibliothek Der Rijksuniversiteit, B.P.L. 135,ff. 87r-93v. (século IX, mss. L); Valenciennes, Bibliothèque Municipale, 393 (olim 376), ff. 112r-123r (século IX, mss. F) e o manuscrito de Veneza, Biblioteca Marciana, Lat.Z. 497 (=1811), ff. 81vb-84vb (século XI, c.1064, mss. M). Este aspecto vale ser salientado, justamente, devido a sua complicada reconstrução estemática (1. iii, p. 21 ss.).

Fixada a filiação genealógica e o modo de transmissão textual, cujos critérios edóticos aplicados na análise refletem não somente os subsídios interpretativos do manuscrito, mas, sobretudo, a natureza específica do texto, o autor passa a considerações acerca da reconstrução 
estemática do texto. Evidentemente, dada esta natureza do texto ser tão diversa - composta a partir de estratos textuais, gramaticais e literários -, sua reconstrução estemática é complexa. Ademais, importa registrar que tal complexidade se deve, sobretudo, por se tratar de um texto escrito em latim medieval e não no latim clássico. Lembremos aqui que o latim medieval é bastante distinto do latim clássico em seus mais variados aspectos. A natureza do texto medieval, escrito em latim, quando confrontada aos seus modos de transmissão, pode agregar uma profunda complexidade quando se trata de reconstruir seus respectivos graus de familiaridade, classificação, variação, ou mesmo relações ascendentes e descendentes dos manuscritos. De tal modo, destaca Mari (2017, p. 21) que "[...] é oportuno notar que não estamos lidando com um texto clássico, mas com um alto medieval: os erros comuns a toda tradição, portanto, terão que ser examinados com cautela, na medida em que erros de um autor menos instruído ou menos cuidadoso também possam ser revelados". 1

Nos capítulos seguintes, Mari analisa as fontes gramaticais (capítulo iv) e as fontes literárias (capítulo v) que serviram de base para a compilação. Dentre as fontes gramaticais destacam-se: Capro, Cominiano (= Carisio sic), Consêncio, Donato, Eutiques, Hieronymus (? sic), Isidoro, Máximo Vitorino, Pompeu, Prisciano, Sérgio e Servio (? sic). Entre suas fontes literárias citam-se: Coripo, Lucrécio, Horácio, Sisebuto, Virgílio. O sexto capítulo aborda bastante rapidamente os textos afins e coetâneos, em que se destacam autores como Sedúlio Escoto, Murethach, Donato, Cruindmelo (gramático irlandês da primeira metade do século IX), Remígio de Auxerre (comentário sobre o barbarismo), Ars Laureshamensis e a inédita Ars de Bruges (cuja dependência de Sedúlio e Murethach - aponta Mari - é evidente).

No capítulo sete da primeira parte examina-se o problema da língua na composição do Pauca de barbarismo, subdividindo-se o

\footnotetext{
${ }^{1}$ No original, "[...] è opportuno tener presente che non abbiamo a che fare con un testo classico, ma con uno altomedievale: gli errori comuni a tutta la tradizione, dunque, andranno vagliati con cautela, nella misura in cui si potrebbero rivelare anche errori propri di un autore poco colto o poco curato" (tradução minha).
} 
capítulo em três partes: (vii.1 Ortografia e fonologia; vii.2 Morfologia; vii.3 Sintaxe e Semântica). Em seguida, Mari, no capítulo intitulado "Contextualização da obra", sugere (com razões) que a obra Pauca de barbarismo foi composta entre 613 (ano de composição do Carmen di Luna do rei visigodo Sisebuto) e a primeira metade do século IX. A primeira parte do texto se encerra com uma contextualização históricocultural e uma explanação sobre os "Critérios editoriais" (capítulo ix) para a edição do texto.

A segunda parte do livro traz a edição do texto que vem acompanhada de um rico aparato crítico, incluindo comparações pontuais do texto com a tradição manuscrita das fontes. Indubitavelmente, o longo esforço do trabalho filológico realizado por Mari merece atenção e valor. $\mathrm{Na}$ introdução de sua edição, ele apontou os problemas encontrados e as suas respectivas soluções, coadunando com a crítica textual, cujos critérios adotados ao longo da edição denotam, por fim, um esforço no sentido de melhor encaminhar o texto em seguida. O texto reconstituído demonstra de forma direta como variantes encontradas dialogam com a tradição do manuscrito, as indicações codicológicas e edóticas traduzindose, por fim, na exegese hermenêutica do pormenor. O vigoroso trabalho de Tommaso Mari destina-se a todos os estudiosos da tradição gramatical do latim medieval e tardio e reflete a sobriedade de um estudo que busca contemplar os diferentes aspectos de sua intrincada composição.

Recebido em: 21 de junho de 2018. Aprovado em: 22 de outubro de 2018. 